\title{
O053. Interictal cerebral posterior circulation in migraineurs with aura: a trancranial color-coded duplexsonography pilot study
}

\author{
Antonio Siniscalchi ${ }^{*}$, Luca Gallelli ${ }^{2}$, Rosario lannacchero ${ }^{3}$ \\ From Abstracts from the 1st Joint ANIRCEF-SISC Congress \\ Rome, Italy. 29-31 October 2015
}

\section{Background}

Vascular cerebral dysfunction restricted to the posterior circulation in migraineurs has been reported. In this preliminary study we compared mean flow diastolic velocity in the posterior cerebral artery during visual stimulation in interictal state headache-free subjects and migraineurs with aura.

\section{Matherials and methods}

Trancranial color-coded duplexsonography was used to assess mean flow diastolic and systolic velocity changes in the posterior cerebral artery, in particular P2, during visual stimulation.

\section{Results}

An increase in vascular reactivity of mean flow diastolic velocity was observed during visual stimulation in headache-free subjects (Group 1, 10 patients) and in the patients affected by migraine with aura (Group 2, 7 patients), without any differences between right and left sides. Reactivity of mean flow diastolic velocity to visual stimulation was found significantly higher in Group 2 (mean \pm SD, $42 \% \pm 2.6 \%$ ) vs Group 2 (mean SD, $33.6 \% \pm 1.8 \%)(\mathrm{p}<0.001)$. In contrast, no differences in flow systolic velocity between the two groups were observed.

\section{Conclusions}

These results indicate that occipital cortex is involved in migraineur patients with aura. Moreover, these patients

\footnotetext{
* Correspondence: anto.siniscalchi@libero.it

${ }^{1}$ Department Neurology, Coordinator DAMA (Disabled Advanced Medical

Assistance), "Annunziata" Hospital, Cosenza, Italy

Full list of author information is available at the end of the article
}

exhibit a larger cerebrovascular response during visual stimulation compared to headache-free subjects.

Written informed consent to publish was obtained from the patient(s).

\section{Authors' details}

'Department Neurology, Coordinator DAMA (Disabled Advanced Medical Assistance), "Annunziata" Hospital, Cosenza, Italy. Department of Health Science, School of Medicine, University of Catanzaro, Clinical Pharmacology and Pharmacovigilance Unit, Mater Domini University Hospital, Catanzaro, Italy. ${ }^{3}$ Department of Neurology, Regional Headache Research Center, "Pugliese-Ciaccio" Hospital, Catanzaro, Italy.

Published: 28 September 2015

doi:10.1186/1129-2377-16-S1-A159

Cite this article as: Siniscalchi et al:: 0053. Interictal cerebral posterior circulation in migraineurs with aura: a trancranial color-coded duplexsonography pilot study. The Journal of Headache and Pain 2015 16(Suppl 1):A159.

\section{SpringerOpen ${ }^{\circ}$}

(c) 2015 Siniscalchi et al. This is an Open Access article distributed under the terms of the Creative Commons Attribution License (http://creativecommons.org/licenses/by/4.0), which permits unrestricted use, distribution, and reproduction in any medium, provided the original work is properly cited. The Creative Commons Public Domain Dedication waiver (http://creativecommons.org/ publicdomain/zero/1.0/) applies to the data made available in this article, unless otherwise stated. 